\title{
Application of Chemically Modified Industrial Slag to As(III) Adsorption from Wastewater: Kinetics and Mass Transfer Analysis
}

\author{
Arijit Dutta Gupta, ${ }^{1}$ Vivek Jaiswal, ${ }^{2}$ Vivek Bhadauria ${ }^{3}$ and Harinder Singh ${ }^{1, \star}$ \\ ${ }^{1}$ Department of Chemical Engineering, Motilal Nehru National Institute of Technology Allahabad, Prayagraj - 211004, India \\ ${ }^{2}$ Department of Chemical Engineering \& Technology, Indian Institute of Technology (BHU), Varanasi - 221005, India \\ ${ }^{3}$ Department of Chemistry, Ewing Christian College, Prayagraj - 211003, India \\ * Corresponding author: E-mail: harinderpdfb@gmail.com \\ Mob. No.:- +91-9936393111
}

Received: 07-25-2020

\begin{abstract}
In the present study, brick kiln slag (BKS) has been utilized for low concentration As(III) adsorption in batch mode. BKS was modified with $\mathrm{H}_{2} \mathrm{SO}_{4}(\mathrm{SA})$ and $\mathrm{NaOH}(\mathrm{SB})$ for enhancing As(III) uptake capacity. Maximum adsorption capacity $(13.7 \mathrm{mg} / \mathrm{g})$ was observed for SA at $298 \mathrm{~K}, \mathrm{pH}=7.0$, adsorbent dose $=0.3 \mathrm{~g}$ and time $=70 \mathrm{~min}$ which was 1.4 times higher than that of SB. Adsorption data modelled into Freundlich isotherm and pseudo-second-order kinetics. Mass transfer coefficients decreased with increase in As(III) concentration. Film diffusion significantly dominated the adsorption of As(III) ions irrespective of the initial concentration. Dimensionless Sherwood number (Sh) interrelated As(III) concentration $\left(C_{o}\right)$ as: $S h=2.97\left(C_{o}\right)^{-0.376}, S h=4.12\left(C_{o}\right)^{-0.215}, S h=4.83\left(C_{o}\right)^{-0.588}$ for $\mathrm{H}_{2} \mathrm{SO}_{4}$ modified, $\mathrm{NaOH}$ modified and native slag respectively. Low temperature $(298 \mathrm{~K})$ favoured As(III) adsorption (based on $\Delta G^{\circ}$ value). Therefore, the modified slag can be used as an effective adsorbent for As(III) remediation from groundwater.
\end{abstract}

Keywords: As(III) adsorption; industrial slag; mass Transfer; film diffusion; sherwood number

\section{Introduction}

In the recent years, rapid industrialization has led to an alarming increase in the contamination of heavy metals in soil and water bodies due to accumulation of various pollutants discharged from the industrial waste water. Imprudent use of such metalloids and heavy metals causes to concentrate in aquatic flora and fauna via discharge in the water bodies. Arsenic is a metalloid with atomic number 33. The earth's crust comprises of about $0.00005 \%$ of arsenic. Rocks and other minerals contain about $0.5-2.5 \mathrm{mg} / \mathrm{kg}$ and usually occur in combination with other metals or non-metals, sulphur and phosphorites. ${ }^{1-3}$ Mobilization of arsenic takes place either in the form of natural phenomena such as weathering, volcanic eruptions, mining of gold, combustion of fossil fuels, smelting processes, agricultural pesticides or leaching of synthetic arsenic pollutants via soil. ${ }^{4}$ Long term exposure to arsenic in drinking water causes lung, kidney and skin cancer, disordering of bone marrow and cartilages, neurological disorders, cardiovascular diseases, abdominal pain and gastrointestinal diseases. Due to its high toxicity on human health, WHO and USEPA have fixed a global maximum permissible limit of $10 \mathrm{ppb}$ or $0.01 \mathrm{ppm}$ for arsenic in drinking water. ${ }^{1}$

Adsorption is a time dependent separation process. The transport of As(III) from the adsorbate (liquid phase) to the adsorbent (solid phase) is typically carried out by mass transfer operation due to the presence of concentration gradient between the adsorbate and the adsorbent. The slowest of these steps is the rate-determining step and is said to control the overall adsorption process. Moreover, in a well agitated batch adsorber, liquid mixing is quite rapid. Therefore, a uniform concentration is assumed between the adsorbate concentration and the solute particles within the system. This step is also referred as the equilibrium step, because the equilibrium between the solute in the bulk adsorbate and the solute on the film of the adsorbent is achieved instantaneously. Therefore, adsorption 
process mainly constitutes two types of mass transfer resistances i.e. external and internal diffusion resistances. The rate limiting step depends on various physical factors such as size of the adsorbent particle, solute affinity for the particular adsorbent and the degree of mixing.,

Difference in chemical potential acts as the driving force for any mass transfer operation which is well defined through their thermodynamic gradients. For any mass transfer operation or any separation processes, theoretical extent of a given separation depends on the position of thermodynamic equilibrium, while the actual rate of separation depends on the rate of mass transfer which is manifested by additional parameters such as flow patterns and diffusivities of the given species in a particular phase. ${ }^{6}$ The actual rate of mass transfer is quantified through the application of various mass transfer coefficients. Such mass transfer coefficients are generally represented in terms of dimensionless numbers such as Sherwood numbers, Transport numbers etc. ${ }^{7}$

Various chemically modified adsorbents for As(III) adsorption have been reported in literature. As(III) adsorption using chemically modified activated carbon was reported to show an adsorption capacity of around 8.7 $\mathrm{mg} / \mathrm{g} .{ }^{8}$ Chemical modification of water melon rind showed a maximum arsenic removal percentage of around $94 \% .{ }^{9}$ Arsenic removal using stainless steel slag was found to show an adsorption capacity of $13.7 \mathrm{mg} / \mathrm{g}^{10}$ Chemical modification of pine wood biochar by Wang et al., 2015 was found to exhibit maximum arsenic capacity of 5.0 $m g / g .{ }^{11}$ Iron ore scrap exhibited an As(III) adsorption capacity of $0.74 \mathrm{mg} / \mathrm{g}^{12}$ However, these studies dealt with high initial concentration of As(III) ions which required a large mass transfer driving force and was easily separable.

The objective of the present study is to determine the applicability of brick kiln slag, as an industrial waste as an adsorbent for low concentration As(III) ions from water. Chemical modification of the slag has been done in order to increase the the affinity for As(III) adsorption. Mass transfer coefficients have been evaluated through the use of various mass transfer models to determine the rate controlling step for adsorption of As(III) using native and chemically modified brick kiln slag. Since the study of mass transfer analysis for adsorption of As(III) adsorption is limited in the literature, this work is being reported for the first time in literature wherein the rate-limiting steps have been determined through various mass transfer models and dimensionless numbers for batch adsorption of As(III) ions.

\section{Materials and Methods}

All chemicals were of AR grade without further purification. Sulphuric acid $\left(\mathrm{H}_{2} \mathrm{SO}_{4}\right)$, hydrogen peroxide $\left(\mathrm{H}_{2} \mathrm{O}_{2}\right)$, sodium arsenite $\left(\mathrm{NaAsO}_{2}\right)$ and sodium hydroxide $(\mathrm{NaOH})$ were purchased from Merck. The glass wares were cleaned with $1 \%$ potassium dichromate and $\mathrm{HNO}_{3}$ solution and rinsed several times with distilled water before use.

\section{1. Preparation of Adsorbents}

The brick kiln slag (BKS) was collected from a local brick kiln from Prayagraj District, India. Prior to chemical modification, the brick kiln slag was washed several times with double distilled water to remove the suspended impurities thereafter chemical activation was done using $10 \%$ $(\mathrm{v} / \mathrm{v})$ hydrogen peroxide $\left(\mathrm{H}_{2} \mathrm{O}_{2}\right)$ and subsequently dried in a hot air oven at $100^{\circ} \mathrm{C}$ for $24 \mathrm{~h}$. The obtained kiln slag was modified with $0.5 \mathrm{M}$ solution of $\mathrm{H}_{2} \mathrm{SO}_{4}$ and $\mathrm{NaOH}$ at room temperature followed by stirring for another $6 \mathrm{~h}$. The obtained adsorbents were the sonicated for another $30 \mathrm{~min}$ at $30{ }^{\circ} \mathrm{C}$ to prevent agglomeration of flocs. The mixture was then centrifuged and washed several times with distilled water and ethanol till the $\mathrm{pH}$ of the supernatant was neutral. The adsorbent samples were then dried in a hot air oven at $120^{\circ} \mathrm{C}$ overnight and stored in desiccators for further use. The synthesised adsorbents were labelled as SN, $\mathrm{SA}$ and $\mathrm{SB}$ respectively, for native, acid modified and alkali modified slag.

\section{2. Physical Properties of the Native and Modified Brick Kiln Slag}

Volume of the adsorbent particles was measured by taking $100 \mathrm{~g}$ of adsorbent in a $250 \mathrm{~mL}$ measuring cylinder which was compacted by tapping up to 20-25 times to ensure absence of any voids. Bulk density was determined by dividing the mass of the adsorbent with the volume. Particle size of the adsorbents was determined by using standard test sieve. The adsorbent samples were placed on the sieve covered with a lid and a pan at the bottom and shaken at $350 \mathrm{rpm}$ for $30 \mathrm{~min}$. The particles with specific size were collected on the pan. Point of zero charge $\left(\mathrm{pH}_{\mathrm{PZC}}\right)$ was determined by $\mathrm{NaCl}$ method. Briefly, $0.01 \mathrm{M} \mathrm{NaCl}$ was prepared and its $\mathrm{pH}$ was adjusted between 1.0-13.0 using $1 \mathrm{M} \mathrm{HCl}$ and $\mathrm{NaOH} .50 \mathrm{~mL}$ of $\mathrm{NaCl}$ at different $\mathrm{pH}$ was taken and $0.2 \mathrm{~g}$ of the adsorbent was added to the flasks and shaken for $24 \mathrm{~h}$ at $350 \mathrm{rpm}$. Final pH was measured after $24 \mathrm{~h}$ and $\mathrm{pH}_{\mathrm{PZC}}$ was determined from the graph between $\mathrm{pH}$ change against initial $\mathrm{pH}$ (Figure 1). Porosity was determined from the SEM analysis. Surface area per unit volume was determined from the relation in Eq. (1):

$$
A=\frac{6 M}{V d_{p} \rho(1-\varepsilon)}
$$

where $V$ is the adsorbate volume in $L, M$ is the mass of the adsorbent in $g, d_{p}$ is the particle diameter in $m, \varepsilon$ is the particle porosity and $\rho$ is the bulk density of the adsorbent in $\mathrm{g} / \mathrm{cm}^{3}$. The physical properties of the native and the chemically modified slag have been summarised in Table 1. 


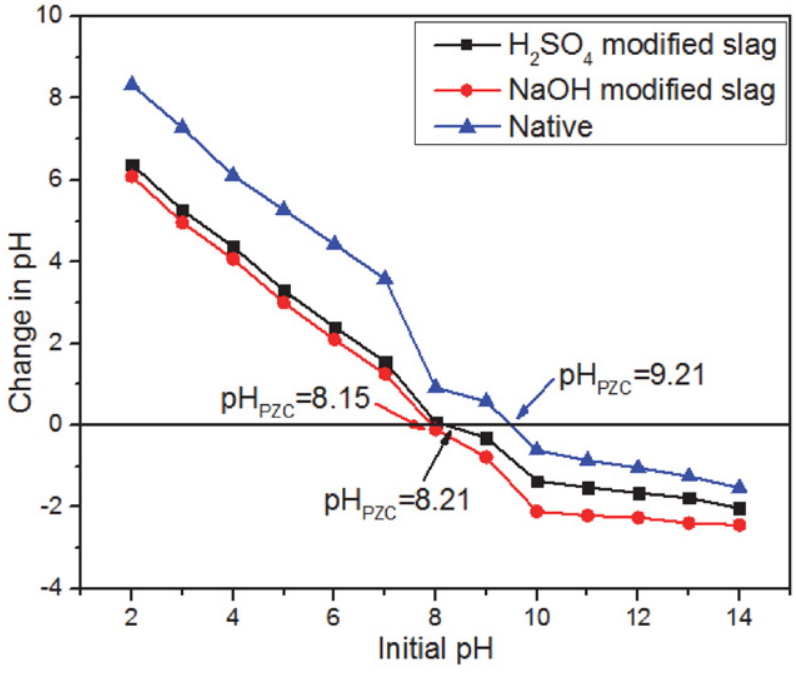

Figure 1. Point of zero charge $\left(\mathrm{pH}_{\mathrm{PZC}}\right)$ of the synthesised adsorbents

Table 1. Physical properties of the native and chemically modified brick kiln slag (BKS)

\begin{tabular}{lccc}
\hline Properties & $\begin{array}{c}\text { Native } \\
\text { BKS }\end{array}$ & $\begin{array}{c}\mathbf{H}_{2} \mathrm{SO}_{4} \\
\text { modified } \\
\text { BKS }\end{array}$ & $\begin{array}{c}\text { NaOH } \\
\text { modified } \\
\text { BKS }\end{array}$ \\
\hline Bulk density $\left(\mathrm{g} / \mathrm{cm}^{3}\right)$ & 1.78 & 1.82 & 1.84 \\
Particle size $(\mu \mathrm{m})$ & 10.05 & 9.34 & 9.45 \\
$\begin{array}{l}\text { Porosity } \\
\text { Point of zero charge } \\
\text { (pH }\end{array}$ & 0.231 & 0.265 & 0.248 \\
$\begin{array}{l}\text { Surface area per unit } \\
\text { volume of the particle }\end{array}$ & 9.12 & 8.21 & 8.15 \\
$\left(m^{-1}\right)$ & 12685.6 & 12795.5 & 12845.7 \\
& & & \\
\hline
\end{tabular}

\section{3. Batch Adsorption Experiment}

In a batch adsorption experiment, influence of various adsorption parameters (time, adsorbent dose and $\mathrm{pH}$ ) on the removal percentage of As(III) was studied. Stock solution of $1000 \mathrm{mg} / \mathrm{L}$ As(III) was prepared by dissolving $0.1734 \mathrm{~g} \mathrm{NaAsO}_{2}$ in $100 \mathrm{~mL}$ of distilled water. Adsorption experiments were carried out by dilution of the stock by varying the initial adsorbate concentration from 1 to 5 $m g / L$ at $\mathrm{pH}=7.0 . \mathrm{pH}$ adjustment was done using $0.1 \mathrm{M}$ $\mathrm{HCl}$ and $\mathrm{NaOH}$ solution. $100 \mathrm{~mL}$ of known concentration of As(III) solution was taken in a $250 \mathrm{~mL}$ Erlenmayer flask. After $\mathrm{pH}$ adjustment, known amount of adsorbent was added and was magnetically stirred $(200 \mathrm{rpm})$ at room temperature $\left(25 \pm 2{ }^{\circ} \mathrm{C}\right)$ until the attainment of equilibrium. Presence of As(III) in solution was determined by variamine oxidation method. ${ }^{13}$ Briefly, aliquot of arsenic containing water was taken in $10 \mathrm{~mL}$ calibrated flasks. Following this, $1 \mathrm{~mL}$ each of $2 \% \mathrm{KIO}_{3}$ and $0.4 \mathrm{M} \mathrm{HCl}$ were added and the mixture was shaken gently for $10 \mathrm{~min}$. Then, $1 \mathrm{~mL}$ of $0.05 \%$ variamine blue and $2 \mathrm{~mL}$ of $2 \mathrm{M} \mathrm{CH}_{3} \mathrm{COO}$ $\mathrm{Na}$ were added. The resultant solution was left undisturbed for 5 min and made up to the mark with distilled water. Reagent blank was prepared simultaneously with distilled water following the same procedure. The absorbance was measured using UV spectrophotometer at $556 \mathrm{~nm}$ against the corresponding reagent blank. The As(III) ions capacity at equilibrium was determined from the Eq. (2):

$$
q_{e}=\frac{\left(C_{i}-C_{e}\right)}{m} \times V
$$

The removal percentage was calculated from the Eq. (3):

$$
\% \text { Removal }=\frac{\left(C_{i}-C_{e}\right)}{C_{i}} \times 100
$$

where $q_{e}$ is the adsorption capacity at equilibrium $(\mathrm{mg} / \mathrm{g})$, $C_{i}$ and $C_{e}$ are the initial and equilibrium adsorbate concentration $(m g / L), m$ is the adsorbate mass $(g), V$ is the volume of the solution $(L)$.

\section{4. Adsorbent Characterizations}

The adsorbent samples were washed with acetone, dried in hot air oven, pulverised and then subjected to gold coating in a vacuum sputtering unit for $15 \mathrm{~min}$ to increase the conductivity of the samples. SEM analysis of the adsorbent samples was done using Zeiss Evo MA-15 scanning electron microscope. The adsorbent samples were dried in an oven to remove any residual moisture and FTIR analysis was performed using PerkinElmer Spectrum Version 10.03.06. X-Ray Diffraction analysis was carried out using Rigaku Smart Lab 3KW X-Ray diffractometer at $2 \theta=5^{\circ}$ $70^{\circ}$ with a step size of $0.02^{\circ}$ using $\mathrm{Cu}-\mathrm{Ka}$ radiation at $50 \mathrm{kV}$ voltage and $40 \mathrm{~mA}$ current.

\section{5. Theoretical Mass Transfer Models}

In any adsorption process, the transfer of adsorbate from the bulk solution to the solid adsorbent takes place either due to film diffusion or internal pore diffusion. The rate limiting step is determined from the slowest of these steps. Therefore, in order to determine the rate controlling step, various theoretical mass transfer models and dimensionless numbers have been studied in the present research.

\section{5. 1. External Diffusion Model}

Liquid film diffusion or external diffusion model plays an important role in adsorption, when there is transfer of molecules from the bulk adsorbate solution to the solid phase adsorbent boundary. This model assumes the fact that the adsorbate concentration at the solid adsorbent's surface tends to zero or intraparticle diffusion resistance is negligible and thus can be neglected at the initial stages of adsorption. This model is derived based on Fick's 
first law of diffusion expressing difference in solute concentrations in the bulk adsorbate and that at the adsorbent's interface as a function of time. ${ }^{14}$ The change in the solute concentration as a function of time can be written as in Eq. (4):

$$
\frac{d C}{d t}=-k_{f} A\left(C-C_{o}\right)
$$

The above equation may be simplified as:

$$
\left[\frac{d\left(\frac{C}{C_{0}}\right)}{d t}\right]_{t \rightarrow 0}=-k_{f} A
$$

where $C$ is the bulk adsorbate concentration in $m g / L$ at any time $t, C_{o}$ is the initial adsorbate concentration in $m g / L, k_{f}$ is the external mass transfer coefficient in $\mathrm{m} / \mathrm{s}$ and $A$ is the surface area per unit volume $\left(\mathrm{m}^{-1}\right)$ calculated from Eq. (1). External mass transfer coefficient $k_{f}$ can be determined from the slope of the dimensionless cure of $C / C_{o}$ against time $(t)$.

\section{5. 2. Boyd Model}

An exact mechanism of As(III) adsorption is easier to predict by examining the differences between the intraparticle and external diffusion model. The equation for Boyd mass transfer model is represented in Eq. (6):

$$
\begin{aligned}
& F=1-\frac{6}{\pi^{2}} \exp (-B t) \\
& F(t)=\frac{q_{t}}{q_{e}}
\end{aligned}
$$

where $F(t)$ is the fraction of As(III) ions adsorbed at any time $t$ and $B t$ is a mathematical function of $F$. The above equation may be simplified as shown in Eq. (8):

$$
B t=[-0.4977-\ln (1-F)]
$$

For the adsorption process to be controlled by film diffusion, the plot of $[-0.4977-\ln (1-F)]$ against $t$ should not pass through origin.

\section{5. 3. McKay et al. Model}

This model is used to analyse the effect of mass transfer resistance on the rate of adsorption. The mass transfer coefficient $\beta_{L}$ in $\mathrm{m} / \mathrm{s}$ of $\mathrm{As}$ (III) at the adsorbate-adsorbent interface can be determined by Eq. (9):

$$
\begin{aligned}
& \ln \left(\frac{c}{c_{o}}-\frac{1}{1+m K}\right)=\ln \left(\frac{m K}{1+m K}\right)-\left(\frac{1+m K}{m K}\right) \beta_{L} A t \\
& K=q_{m} \times k_{L}
\end{aligned}
$$

where $q_{m}$ is the maximum adsorption capacity in $m g / g$ and $k_{L}$ is the Langmuir constant in $L / m g$. $\beta_{L}$ is calculated from the slope of the linear plot of $\ln \left(\left(C / C_{o}\right)-1 /\left(1+m k_{L}\right)\right)$ vs time $(t)$.

\section{5. 4. Dimensionless Numbers}

\section{5. 4. 1. Sherwood Number}

Sherwood Number $(S h)$ relates the rate of adsorption as a function of adsorbate concentration in terms of external and internal mass transfer resistances. It is the ratio of rate of solute transfer across the adsorbate (liquid) surface to the rate of intraparticle mass transport. It is expressed in the form of Eq. (11):

$$
S h=\left(\frac{k_{f}}{D_{e}}\right)\left(\frac{d}{\rho}\right)\left(\frac{C_{o}}{q_{m}}\right)
$$

where $\rho$ is he particle density in $\mathrm{g} / \mathrm{cm}^{3}$ and $q_{m}$ is the maximum adsorption capacity in $\mathrm{mg} / \mathrm{g}$ (calculated from Langmuir isotherm model). The conventional form of Sherwood Number is expressed in the form of Eq. (12):

$$
S h=\frac{k_{f} d}{D_{e}}
$$

The process is film diffusion controlled if $S h<1.0$, while $S h>1.0$ infers intraparticle diffusion as the rate-limiting step.

\section{5. 4. 2. Transport Number}

Transport Number $(n)$ is used to determine the mode of diffusion. It is shown in Eq. (13):

$$
\frac{q_{t}}{q_{e}}=K_{m} t^{n}
$$

where $K_{m}$ is the adsorbent-adsorbate interaction constant and $n$ is the transport number. A plot of $\log \left(q_{t} / q_{e}\right)$ vs. $\log t$ yields a straight line from which $K_{m}$ and $n$ can be determined from the y-intercept and slope respectively. If $n=1$, non-Fickian mechanism is inferred while $n=0.5$, represents Fickian (surface) mechanism.

\section{Results and Discussion}

\section{1. Adsorbent Characterizations}

\section{1. 1. Fourier Transform Infrared Spectroscopy (FTIR)}

The FTIR spectra of the native and modified adsorbents before and after adsorption is shown in Figure 2. The sharp peak around $3500 \mathrm{~cm}^{-1}$ represents $\mathrm{H}-\mathrm{O}-\mathrm{H}$ stretching was due to the presence of moisture in the samples. The major peak corresponding to $1050 \mathrm{~cm}^{-1}$ was attributed to asymmetric stretching of Si-O-T bonds $(\mathrm{T}=\mathrm{Si}$ or $\mathrm{Al})$. The peak intensity was found to be relatively less in SA adsor- 

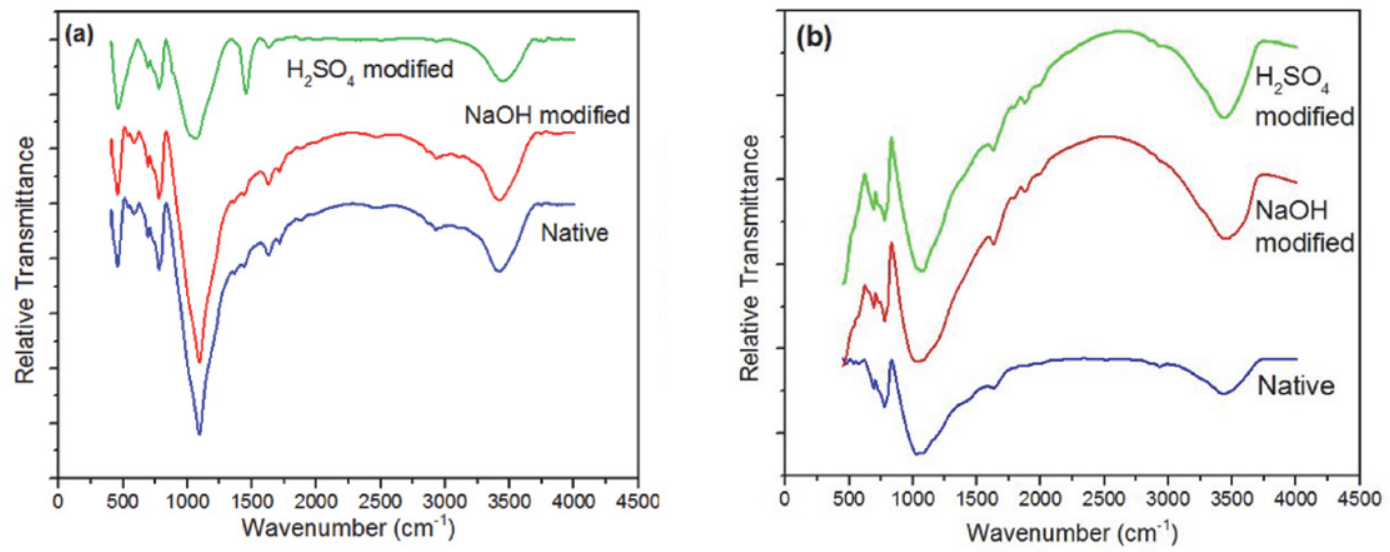

Figure 2. FTIR spectra of the synthesised adsorbents (a) before and (b) after adsorption of As(III)

bent as compared to SN and SB. This may be due to the reaction between silicon (II) oxide and sulphuric acid resulting in the formation of sulphur dioxide and water. ${ }^{15}$ Another sharp peak was observed at $1490 \mathrm{~cm}^{-1}$ in the FTIR spectra of acid modified slag (SA) which indicated the presence of stretched vibrations of O-C-O bonds of $\mathrm{CO}_{3}{ }^{2-}$. The peak corresponding to $870 \mathrm{~cm}^{-1}$ which was present in all adsorbent samples was attributed to the asymmetric stretched vibrations of tetrahedral aluminium ions which confirmed the presence of $\mathrm{AlO}_{4}$ and $\mathrm{SiO}_{4}$ in different configurations. ${ }^{16}$ The absorption bands of slag consisting of clay showed stretching and bending of $\mathrm{Si}-\mathrm{O}$ as well as bending of $\mathrm{O}-\mathrm{H}$ groups from $1300-1450 \mathrm{~cm}^{-1}$ in all the adsorbent samples. A peak around $750-780 \mathrm{~cm}^{-1}$ may be attributed to the presence of vibrational Si-O-Al bonds indicating the presence of feldspar in all the samples. The bands around 500$550 \mathrm{~cm}^{-1}$ were assigned to octahedral Si-O-Al and Si-O-Si respectively. A small peak at $790 \mathrm{~cm}^{-1}$ which was present in all adsorbents was attributed to the presence of quartz. ${ }^{17}$

\section{1. 2. X-Ray Diffraction Analysis (XRD)}

Figure 3 shows the XRD diffraction patterns of the native and modified slag. The presence of sharp peak around $2 \theta=25^{\circ}$ in the acid and alkali modified slag indicated greater crystallinity as compared to the native slag. The small peak around $2 \theta=20^{\circ}$ was attributed to the pres-

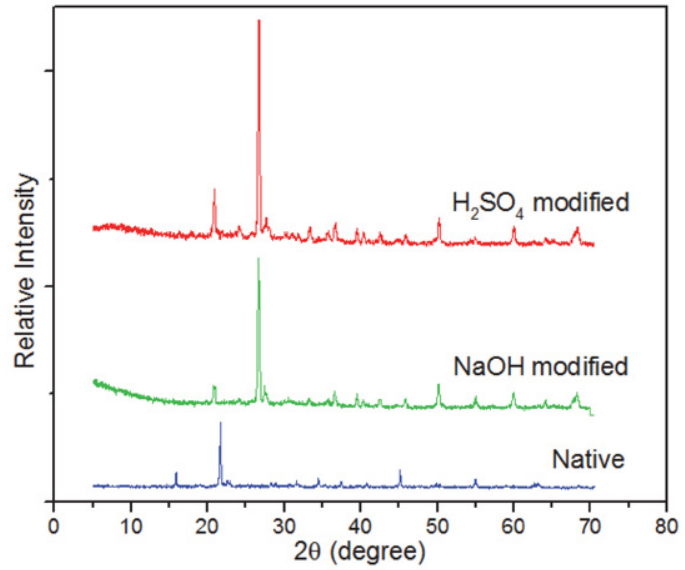

Figure 3. XRD of the native and chemically modified brick kiln slag

ence of feldspars in the adsorbent samples. ${ }^{18}$ However, the intensity of these peaks in the modified adsorbents has been reduced as compared to the native adsorbent. Reaction between acid in SA and alkali in SB adsorbents and sodium silicate in slag resulting in the formation of insoluble precipitated silica may be attributed as one of the reason for this decrease in peak intensity. Presence of cristobalite in all adsorbent samples is confirmed by the presence of minute peaks occurring in $2 \theta=30-60^{\circ}$. Cristobalite is found in many clays such as bentonite, diatomite and has been reported to show adsorption characteristics. ${ }^{19}$
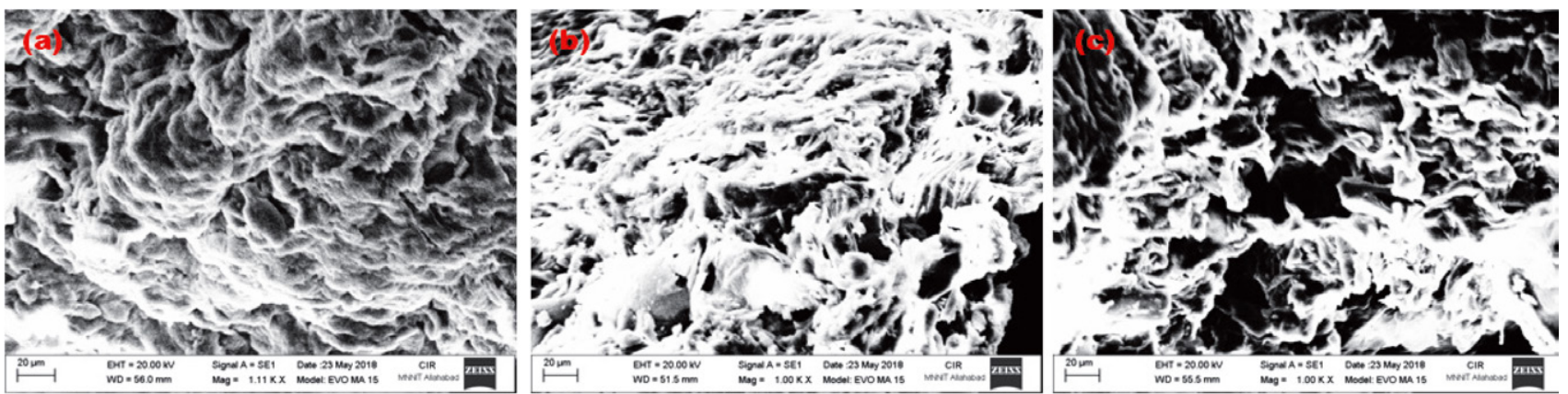

Figure 4. SEM micrographs of (a) $\mathrm{H}_{2} \mathrm{SO}_{4}$ modified slag; (b) $\mathrm{NaOH}$ modified slag; (c) native slag 


\section{1. 3. Scanning Electron Microscopy (SEM)}

The SEM micrographs of the native and modified adsorbents have been shown in Figure 4. Relatively thick and homogeneous morphology resulting from processing of bricks at high temperature was seen in all the adsorbent samples. The modified adsorbent samples represented relatively high porosity as compared to the native. The acid modified adsorbent sample was observed to have porous surface morphology with minute cracks generation. These cracks may have been created due to elevated oxidizing property of $\mathrm{H}_{2} \mathrm{SO}_{4}$ that breaks down the crystal lattice of the calcined clay. However, in the case of alkali modified slag, insoluble sodium silicate was formed when the adsorbent was treated with $\mathrm{NaOH}$ which was washed with water thus resulting in equal and lesser porosity of the $\mathrm{NaOH}$ modified adsorbent as compared to the native. ${ }^{20}$

\section{2. Adsorption Study}

\section{2. 1. Effect of Contact Time}

In order to investigate the effect of time on the adsorption, batch adsorption was performed using $100 \mathrm{~mL}$ of $1 \mathrm{mg} / \mathrm{L}$ of As(III) ions solution using $0.25 \mathrm{~g}$ of each adsorbent. It was observed that the relative removal percentage of As(III) ions increased with contact time with saturation occurring after 75 and 120 min respectively, for acid and alkali modified and native slag (Figure 5(a)). Presence of the concentration gradient between those of the adsorbed and the unadsorbed As(III) ions and the availability of vacant sites provided the necessary driving force for increase in adsorption capacity as a function of time. ${ }^{21}$ Greater number of As(III) ions were adsorbed at the onset of adsorption due to greater number of available active sites. It was also observed that the SB adsorbent exhibited the lesser adsorption capacity than the acid modified slag with the same saturation time. This was probably due to oxidising tendency and greater porosity of the SA adsorbent than that of native. Saturation of the active sites may be ascribed to the presence of repulsive forces between the adsorbed As(III) ions and the bulk adsorbate concentration.

\section{2. 2. Effect of Adsorbent Dose}

The effect of adsorbent dose on removal percentage of As(III) ions has been shown in Figure 5(b). Adsorbent dose was varied from 0.1 to $0.9 \mathrm{~g} / 100 \mathrm{~mL}$ at $\mathrm{pH}=7.0$ in order to study its effect on removal percentage of As(III). Initially the removal percentage of As(III) ions was found to increase with adsorbent dose with saturation reaching at 0.3 and $0.6 \mathrm{~g} / 100 \mathrm{~mL}$ respectively for acid and alkali modified and native slag respectively. Decrease in removal capacity of As(III) ions beyond the equilibrium may be probably due to increase in mass transfer resistance which decreased the relative uptake capacity of As(III) ions from its aqueous solution. ${ }^{22}$ It can also be inferred from Figure 5(b) that the acid modified slag showed greater adsorption capacity than the alkali modified slag with the same adsorbent dose due to the oxidising tendency of acid than that of alkali. Another reason may be attributed to the presence of surface charge resulting in increase of binding tendency of As(III) ions on the surface of the acid modified adsorbent. Lower removal percentage for alkali modified slag than that of acid modified with same adsorbent dose may also be due to the reaction of alkali and silica in slag resulting in the formation of insoluble precipitates of silicates which hindered the adsorption capacity of As(III) ions. ${ }^{20}$

\section{2. 3. Effect of $\mathrm{pH}$}

The $\mathrm{pH}$ of the adsorbate was varied from 2.0 to 10.0 at a fixed adsorbate concentration in order to study its effect on the adsorption capacity of the synthesised adsorbents. It was observed from Figure 5(c) that the adsorption capacity was observed to be quite low at both acidic and alkaline $\mathrm{pH}$. The maximum adsorption took place at $\mathrm{pH}=7.0$ irrespective of the nature of the adsorbent. This was probably due to speciation of $\mathrm{As}$ (III) ions. As(III) ions are predominantly available as $\mathrm{H}_{3} \mathrm{AsO}_{3}$ at $\mathrm{pH}<8.0$ and $\mathrm{H}_{2} \mathrm{AsO}_{3}{ }^{-}, \mathrm{HAsO}_{3}{ }^{2-}$ and $\mathrm{AsO}_{3}{ }^{3-}$ at $\mathrm{pH}>8.0$. From Table 1, it can be observed that the values of $\mathrm{pH}_{\mathrm{PZC}}$ are 8.2, 8.1 and 9.1 respectively, for $\mathrm{H}_{2} \mathrm{SO}_{4}$ modified slag, $\mathrm{NaOH}$ modified slag and native. Consequently, As(III) ions can be adsorbed by the electrostatic force of attraction between the neutral species from the positively charged surface of the adsorbent at a $\mathrm{pH}<\mathrm{pH}_{\mathrm{PZC}}$. The maximum removal percentage at $\mathrm{pH}=7.0$ was probably due to the Van-der-wall's forces of attraction between $\mathrm{H}_{3} \mathrm{AsO}_{3}$ (neutral) and the adsorbent's surface. This may result in the binding of these neutral species to the positively charged surface of the adsorbent. At alkaline $\mathrm{pH}$, the dominating negatively charged species are formed resulting in electrostatic repulsion between the negatively charged surface of the adsorbent and the negatively charged As(III) ions thereby reducing the relative uptake capacity of As(III) ions at alkaline $\mathrm{pH} .{ }^{23}$ Under optimised condition of $\mathrm{pH}(\sim 7.0)$, As(III) ions are capable of binding with the sulphate ions on

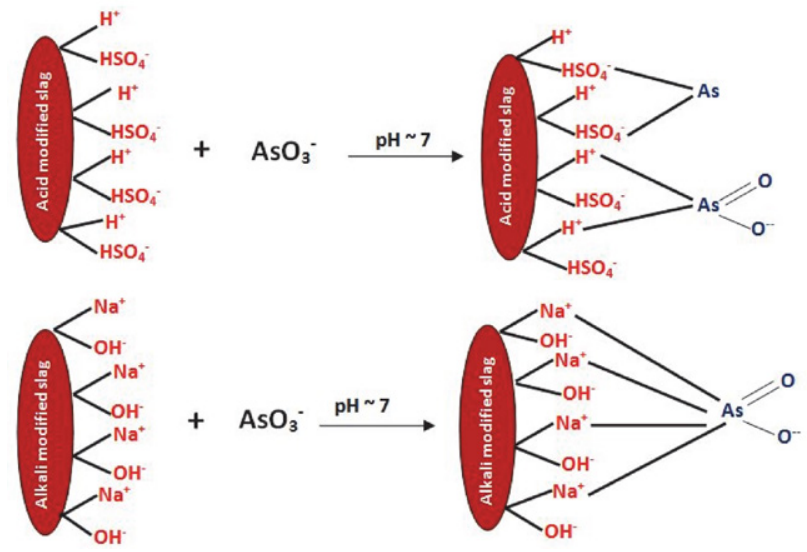

Scheme 1. Schematic representation of the proposed mechanism for As(III) ions adsorption using acid and alkali modified industrial slag at $\mathrm{pH}=7.0$ and temperature $=298 \mathrm{~K}$ 

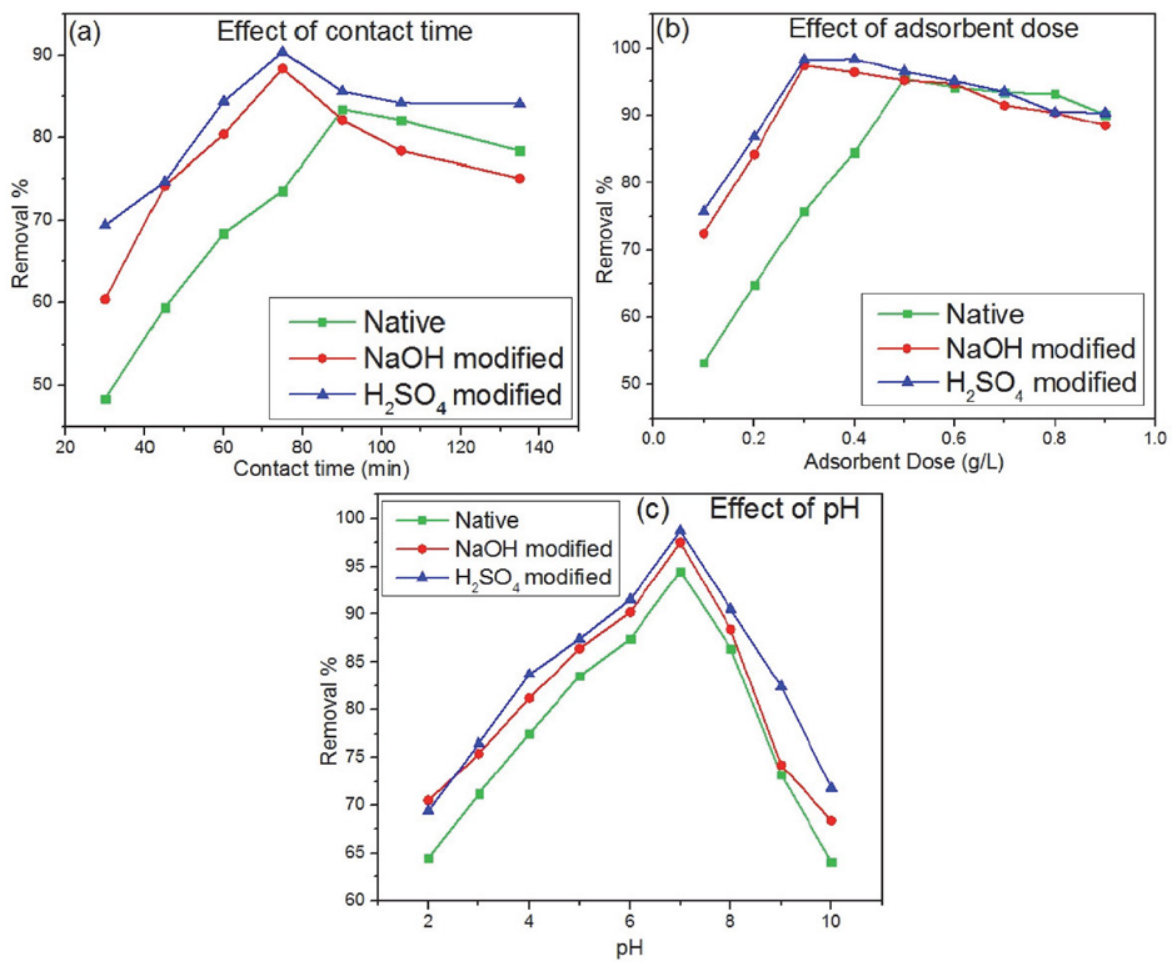

Figure 5. Influence of (a) Contact time; (b) Adsorbent dose; (c) pH on the adsorption of As(III) using native and modified brick kiln slag at $298 \mathrm{~K}$

the surface of the acid modified slag releasing a water molecule as a by-product while arsenate ions can bind with the hydrogen ions forming weak arsenious acid. In the case of alkali modified slag, arsenic (III) oxides have the tendency to bind with the sodium ions forming sodium arsenite. ${ }^{24}$ The probable mechanism has been illustrated in Scheme 1.

\section{3. Adsorption Kinetics}

Kinetics of adsorption dictates the dependence of adsorption capacity with time. Adsorption experiments were performed using $0.3 \mathrm{~g}$ each of SA and SB and $0.6 \mathrm{~g}$ of $\mathrm{SN}$ at $\mathrm{pH}=7.0$ and temperature $=298 \mathrm{~K}$. Acid and alkali modified slag exhibited a rapid uptake time for the first 75 min and then the rate of adsorption decreased and equilibrium was attained in $100 \mathrm{~min}$. In the present study, three kinetic models (pseudo first order kinetic, pseudo second order kinetic and intraparticle diffusion models) have been studied to describe the behaviour of experimental adsorption capacity with time.

Pseudo first order kinetic model is represented in Eq. (14):

$$
\ln \left(q_{e}-q_{t}\right)=\ln q_{e}-k_{1} t
$$

Pseudo second order kinetic model can be represented in Eq. (15):

$$
\frac{t}{q_{t}}=\frac{1}{k_{2} q_{e}^{2}}+\frac{t}{q_{e}}
$$

where $q_{e}$ and $q_{t}$ represents the equilibrium and instantaneous adsorption capacities in $m g / g, k_{1}$ and $k_{2}$ are the first and second order rate constants respectively. Intraparticle diffusion model is represented in Eq. (16):

$$
q_{t}=K_{i d} t^{1 / 2}+C
$$

where $K_{i d}$ is the intraparticle rate constant in $\mathrm{mg} / \mathrm{g} \cdot \mathrm{min}^{1 / 2}$ and $C$ is the y-intercept.

The kinetic plots for As(III) adsorption using native and modified slag have been presented in Figure 6 and the parameters are tabulated in Table 2. It can be seen from the table that the $R^{2}$ values obtained from the pseudo first order kinetic model were less than 0.9 irrespective of the nature of the adsorbent. The obtained values of the first order rate constants $\left(k_{1}\right)$ were $0.033,0.028$ and $0.035 \mathrm{~min}^{-1}$ respectively, for $\mathrm{H}_{2} \mathrm{SO}_{4}$ modified, $\mathrm{NaOH}$ modified and native. The theoretically obtained values of $q_{e}$ were 8.2, 3.2 and $1.2 \mathrm{mg} / \mathrm{g}$, respectively, for $\mathrm{H}_{2} \mathrm{SO}_{4}$ modified slag, $\mathrm{NaOH}$ modified slag and native which were observed to be much lower than the values obtained from the experiments ( 14.2 $\mathrm{mg} / \mathrm{g}$ for $\mathrm{H}_{2} \mathrm{SO}_{4}$ modified slag, $12.05 \mathrm{mg} / \mathrm{g}$ for $\mathrm{NaOH}$ modified slag and $7.32 \mathrm{mg} / \mathrm{g}$ for native slag). Thus, it can be inferred that pseudo first order kinetic model did not give a good correlation with the experimental values irrespective of the type of modification.

The second order rate constant values $\left(k_{2}\right)$ obtained from the pseudo second order kinetic plots were $6.6 \times 10^{-5}$, $3.1 \times 10^{-4}$ and $2.6 \times 10^{-3} \mathrm{~g}\left(\mathrm{mg} . \mathrm{min}^{-1}\right.$, respectively, for $\mathrm{H}_{2} \mathrm{SO}_{4}$ modified slag, $\mathrm{NaOH}$ modified slag and native. The 
Table 2. Estimated kinetic parameters for As(III) adsorption using native and chemically modified slag

\begin{tabular}{|c|c|c|c|c|c|c|c|c|c|}
\hline \multirow[t]{2}{*}{ Adsorbents } & \multicolumn{3}{|c|}{ Pseudo First order kinetics } & \multicolumn{3}{|c|}{ Pseudo Second order kinetics } & \multicolumn{3}{|c|}{ Intraparticle Diffusion model } \\
\hline & $\mathrm{q}_{\mathrm{e}}(\mathrm{mg} / \mathrm{g})$ & $k_{1}\left(\min ^{-1}\right)$ & $\mathbf{R}^{2}$ & $\mathrm{q}_{\mathrm{e}}(\mathrm{mg} / \mathrm{g})$ & $\mathrm{k}_{2}\left(\mathrm{~g}(\mathrm{mg} \cdot \min )^{-1}\right)$ & $\mathbf{R}^{2}$ & $K_{\text {id }}\left(\mathrm{mg} / \mathrm{g} \cdot \min ^{1 / 2}\right)$ & $\mathrm{C}$ & $\mathbf{R}^{2}$ \\
\hline $\begin{array}{l}\text { Acid modified } \\
\text { BKS }\end{array}$ & 8.21 & 0.033 & 0.832 & 10.64 & $6.61 \times 10^{-5}$ & 0.985 & 0.033 & 0.241 & 0.842 \\
\hline $\begin{array}{l}\text { Alkali modified } \\
\text { BKS }\end{array}$ & 3.24 & 0.028 & 0.715 & 5.72 & $3.11 \times 10^{-4}$ & 0.988 & 0.034 & 0.145 & 0.854 \\
\hline Native & 1.12 & 0.036 & 0.851 & 2.25 & $2.41 \times 10^{-3}$ & 0.974 & 0.024 & 0.041 & 0.889 \\
\hline
\end{tabular}

values of the initial rate constant $\left(h=k_{2} \cdot q_{e}^{2}\right)$ were $7.4 \times$ $10^{-3}, 0.012$ and $0.031 \mathrm{mg} / \mathrm{g}$.min, respectively, for $\mathrm{H}_{2} \mathrm{SO}_{4}$ modified slag, $\mathrm{NaOH}$ modified slag and native and were observed to be significantly higher than the rate $k_{2}$ values. This showed that As(III) adsorption over the native and modified slag was quite rapid at the onset of adsorption. ${ }^{24,25}$ Moreover, the $R^{2}$ values (>0.95) obtained from pseudo second order kinetic model showed its goodness of fit with the adsorption data. From the intratparticle diffusion plots (Figure 6(c)), it can be ascertained that the plots does not passes through origin indicating that intraparticle diffusion was not solely the rate controlling mechanism and some degree of film diffusion was expected to occur for As(III) adsorption. In order to have a clear picture of the rate controlling mechanism, mass transfer models have been studied.

The values of $q_{e}$ shown in the above table represent the theoretical values of the equilibrium adsorption capacity calculated from the respective kinetic model equations.

\section{4. Mass Transfer Models}

\section{4. 1. External Diffusion Model}

It was observed from Table 3 that the mass transfer coefficients decreased with increase in the concentration of As(III) ions. Driving force for adsorption is directly proportional to the adsorbate concentration. As the number of active sites on the adsorbent's surface was fixed, the mass transfer coefficients decreased with increase in As(III) concentration. Another reason for this behaviour may be attributed from the adsorption equilibrium theory. Since the external mass transfer coefficient is inversely proportional to the slope of operating lines at equilibrium, the values of external mass transfer coefficient decreased with increase in initial As(III) ions concentration in the bulk solution. The external mass transfer is also said to be the controlling variable when the model is linear. Increase in contact time decreased the strength of boundary layer resistance which significantly increased the mobility of
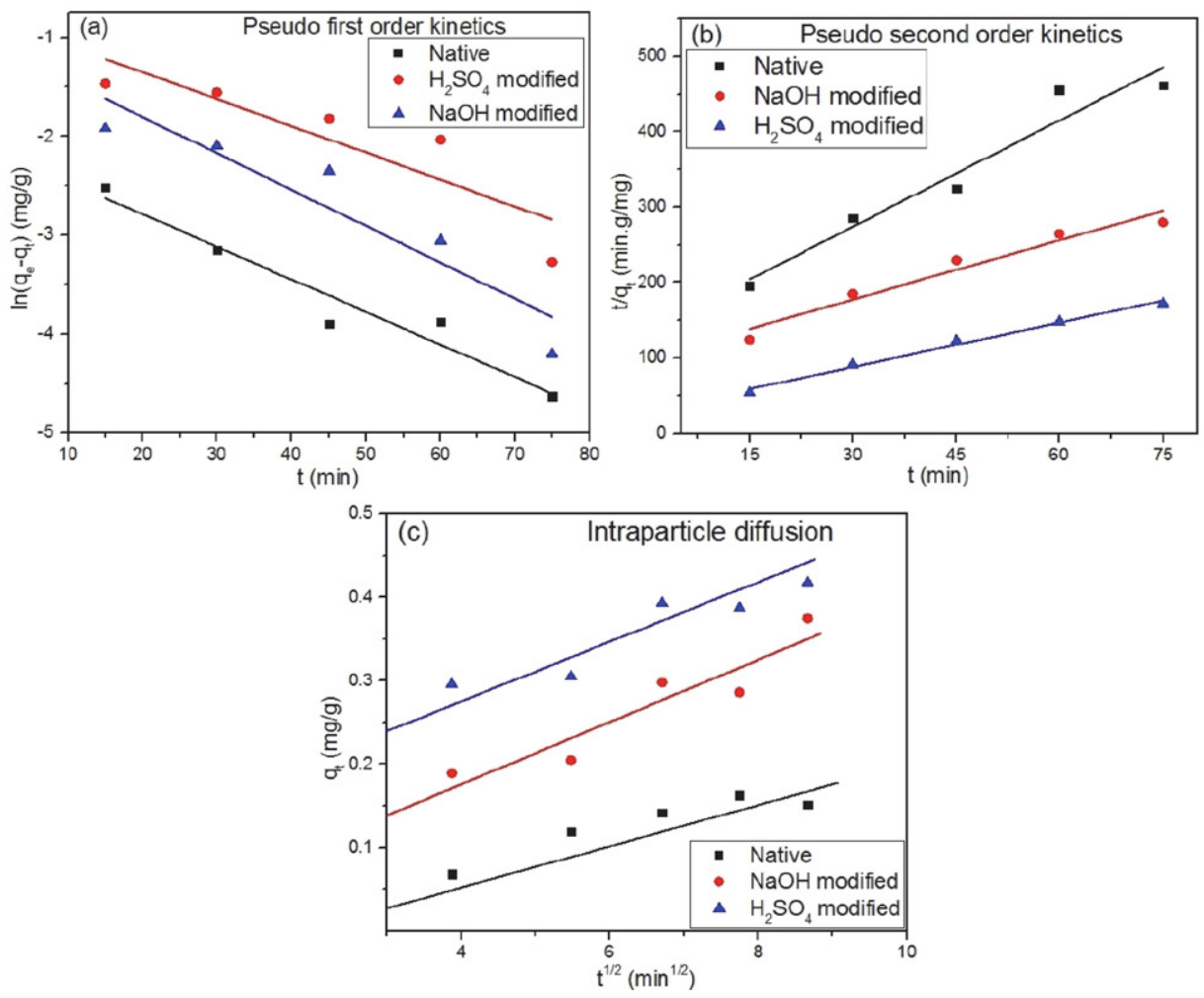

Figure 6. Kinetic plots for As(III) adsorption using native and chemically modified brick kiln slag at $298 \mathrm{~K}$ and $\mathrm{pH}=7.0$ 
Table 3. External Diffusion Model Mass Transfer Coefficients for As(III) adsorption

\begin{tabular}{ccccccr}
\hline$C_{\boldsymbol{o}}$ & \multicolumn{2}{c}{ Native } & \multicolumn{2}{c}{$\mathbf{H}_{\mathbf{2}} \mathbf{S O}_{\mathbf{4}}$ modified } & \multicolumn{2}{c}{$\mathbf{N a O H}$ modified } \\
$(\boldsymbol{m} \mathbf{g} / \mathbf{L})$ & $\mathbf{k}_{\mathbf{f}}(\mathbf{m} / \mathbf{s})$ & $\mathbf{R}^{2}$ & $\mathbf{k}_{\mathbf{f}}(\mathbf{m} / \mathbf{s})$ & $\mathbf{R}^{2}$ & $\mathbf{k}_{\mathbf{f}}(\mathbf{m} / \mathbf{s})$ & $\mathbf{R}^{2}$ \\
\hline 1 & $1.15 \times 10^{-10}$ & 0.982 & $1.49 \times 10^{-10}$ & 0.972 & $1.30 \times 10^{-10}$ & 0.964 \\
2 & $0.85 \times 10^{-10}$ & 0.964 & $1.38 \times 10^{-10}$ & 0.982 & $1.21 \times 10^{-10}$ & 0.976 \\
3 & $0.65 \times 10^{-10}$ & 0.971 & $1.25 \times 10^{-10}$ & 0.958 & $1.12 \times 10^{-10}$ & 0.963 \\
4 & $0.51 \times 10^{-10}$ & 0.975 & $1.07 \times 10^{-10}$ & 0.964 & $1.02 \times 10^{-10}$ & 0.975 \\
5 & $0.39 \times 10^{-10}$ & 0.961 & $0.95 \times 10^{-10}$ & 0.955 & $0.85 \times 10^{-10}$ & 0.985 \\
\hline
\end{tabular}

As(III) ions during the initial stages of adsorption. Thus external mass transfer coefficient cannot be neglected even during the initial stages of adsorption. ${ }^{26}$

\section{4. 2. Boyd Model}

A clear difference between the intraparticle and film diffusion helps to understand the exact rate determining step for As(III) adsorption using native and modified slag. The linear plot of $[-0.4977-\ln (1-F)]$ versus time is shown in Figure 7. The plots does not passes through origin which in an indicative of the film diffusion as the rate determining step in As(III) adsorption using native and modified brick kiln slag. Moreover, the $R^{2}$ values obtained from intraparticle diffusion $\left(R^{2}=0.85\right)$ was significantly lower than those obtained from the Boyd plots $\left(R^{2}=0.96\right)$. This further confirmed the possibility of film diffusion at the onset of adsorption and thereafter intraparticle diffusion. The obtained $B$ values from the linear plots shown in Figure 7 have been used to estimate the effective diffusivity values $\left(D_{i}\right)$ in $m / s$. It is shown in Eq. (17):

$$
B=\frac{D_{i} \pi^{2}}{r^{2}}
$$

where $r$ is the radius of the adsorbent particle in $m$. The estimated $D_{i}$ values were: $0.18 \times 10^{-10}, 0.25 \times 10^{-10}$ and $0.27 \times 10^{-10} \mathrm{~m} / \mathrm{s}$ respectively, for native, $\mathrm{NaOH}$ and $\mathrm{H}_{2} \mathrm{SO}_{4}$ modified slag. These values almost show a similar trend irrespective of the nature of the adsorbent. However, the $D_{i}$ value of $\mathrm{H}_{2} \mathrm{SO}_{4}$ modified slag was slightly higher than $\mathrm{NaOH}$ modified slag. This further confirmed the ease of mobility of As(III) ions from the bulk solution to the $\mathrm{H}_{2} \mathrm{SO}_{4}$ modified slag. These findings clearly show that the

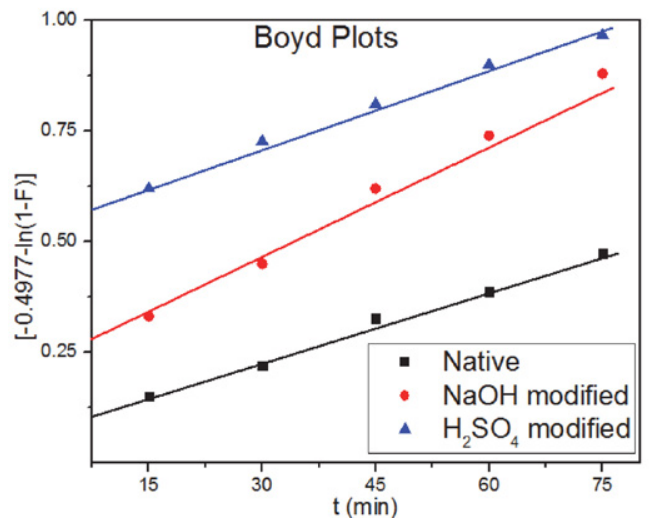

Figure 7. Boyd Mass plots for As(III) adsorption using native and chemically modified brick kiln slag

adsorption of $\mathrm{As}(\mathrm{III})$ ions using native, $\mathrm{H}_{2} \mathrm{SO}_{4}$ and $\mathrm{NaOH}$ modified slag was controlled by film diffusion or surface diffusion at the initial stages followed by intraparticle diffusion.

\section{4. 3. McKay et al Model}

The plots of the experimental adsorption data for As(III) adsorption using native and modified slag at different initial concentrations have been shown in Figure 8 and the estimated mass transfer coefficients $\left(\beta_{L}\right)$ from this model have been summarised in Table 4 . It can be clearly observed that $\beta_{L}$ decreased with increase in initial As(III) concentration irrespective of the type of adsorbent. The values for $\beta_{L}$ showed that the velocity of the As(III) ions to migrate from the bulk liquid phase to the solid adsorbent's surface. ${ }^{27}$ The obtained values of mass transfer coefficients $\left(\beta_{L}\right)$ from this model were observed to be much higher

Table 4. Estimated values of mass transfer coefficients $\left(\beta_{L}\right)$ from McKay et al model

\begin{tabular}{lccccrr}
\hline$C_{\boldsymbol{o}}$ & \multicolumn{2}{c}{ Native } & \multicolumn{2}{c}{$\mathbf{H}_{\mathbf{2}} \mathbf{S O}_{\mathbf{4}}$ modified } & \multicolumn{2}{c}{ NaOH modified } \\
$(\boldsymbol{m} \boldsymbol{g} / \mathbf{L})$ & $\boldsymbol{\beta L}(\mathbf{m} / \mathbf{s})$ & $\mathbf{R 2}$ & $\boldsymbol{\beta L}(\mathbf{m} / \mathbf{s})$ & $\mathbf{R 2}$ & $\boldsymbol{\beta L}(\mathbf{m} / \mathbf{s})$ & $\mathbf{R 2}$ \\
\hline 1 & $2.12 \times 10^{-7}$ & 0.705 & $5.26 \times 10^{-7}$ & 0.605 & $4.21 \times 10^{-7}$ & 0.634 \\
2 & $2.05 \times 10^{-7}$ & 0.635 & $4.15 \times 10^{-7}$ & 0.648 & $3.15 \times 10^{-7}$ & 0.607 \\
3 & $1.25 \times 10^{-7}$ & 0.715 & $3.02 \times 10^{-7}$ & 0.705 & $2.02 \times 10^{-7}$ & 0.615 \\
4 & $0.82 \times 10^{-7}$ & 0.698 & $2.12 \times 10^{-7}$ & 0.687 & $1.11 \times 10^{-7}$ & 0.708 \\
5 & $0.65 \times 10^{-7}$ & 0.714 & $1.08 \times 10^{-7}$ & 0.713 & $0.93 \times 10^{-7}$ & 0.652 \\
\hline
\end{tabular}




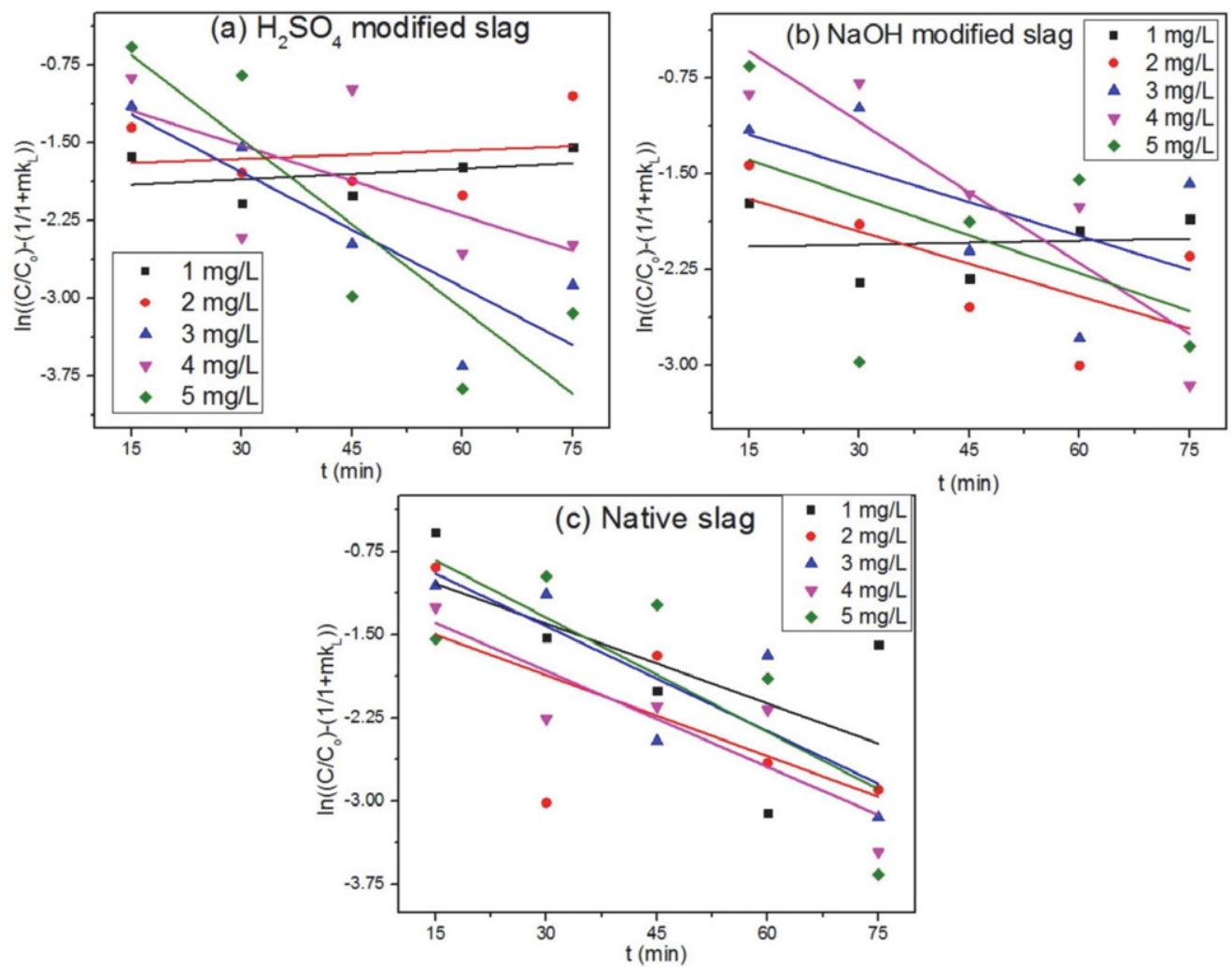

Figure 8. McKay et al mass transfer plots for native and modified slag at different initial As(III) concentrations

than those calculated from the external diffusion model. The linear regression values calculated from this model $\left(R^{2}\right.$ $<0.9$ ) indicated that the ease of migration of As(III) ions from the bulk solution was quite high and thus cannot be inferred as the rate controlling mechanism.

\section{4. 4. Dimensionless Numbers}

\section{4. 4. Sherwood Number}

The influence of initial concentration of As(III) ions on the Sherwood number is shown in Figure 9. The values of the dimensionless number were less than 1.0 indicating the rate of adsorption of As(III) ions on to the native and modified adsorbents was controlled by film mass transfer or surface diffusion. Based on the linearity of the plots, Eqs. (18)-(20) have been obtained for the adsorbent samples modified with $\mathrm{H}_{2} \mathrm{SO}_{4}, \mathrm{NaOH}$ and native respectively. It was observed that Sherwood number decreased with the increase in initial concentration of As(III) ions in the bulk adsorbate phase. Thus, it can be inferred that the rate of mass transfer for adsorption of As(III) ions increased with decrease in the bulk adsorbate concentration.

$$
\begin{gathered}
S h=2.97\left(C_{o}\right)^{-0.376} \\
S h=4.12\left(C_{o}\right)^{-0.215} \\
S h=4.83\left(C_{o}\right)^{-0.588}
\end{gathered}
$$

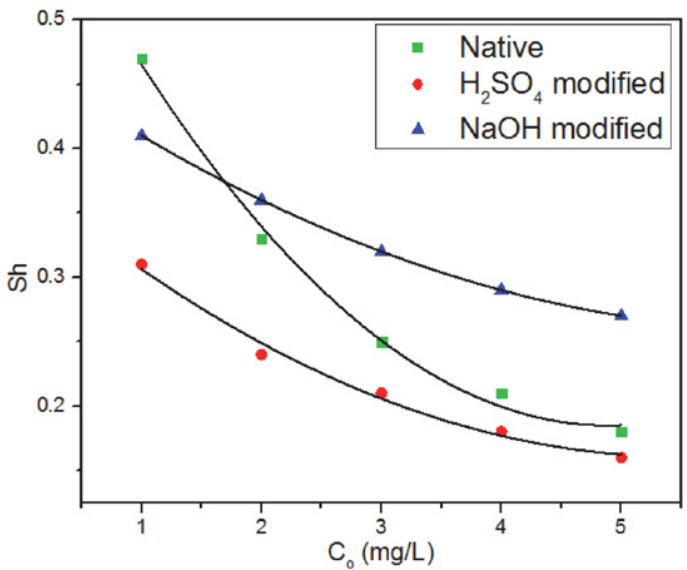

Figure 9. Influence of Sherwood number on initial As(III) concentration using native and chemically modified brick kiln slag

\section{4. 4. 2. Transport Number}

The variation of Transport number with respect to initial As(III) ions concentration has been shown in Table 5 . It was observed that the values of Transport number $(n)$ was almost equal to 0.5 thus showing Fickian diffusion or surface diffusion. This was probably due to interaction of As(III) ions with the surface of the adsorbent through the external film of adsorbate or boundary layer surrounding the adsorbent particle. ${ }^{28}$ Thus, in the present research, it can be inferred that external mass transfer had a dominating effect than intraparticle diffusion. This may be attributed to 
Table 5. Estimated Transport number at various initial concentration of As(III) ions

\begin{tabular}{ccccccc}
\hline $\begin{array}{c}\mathbf{C}_{\mathbf{o}} \\
(\mathbf{m g} / \mathbf{L})\end{array}$ & \multicolumn{2}{c}{ Native } & \multicolumn{2}{c}{$\mathbf{H}_{\mathbf{2}} \mathbf{S O}_{\mathbf{4}}$ modified } & \multicolumn{2}{c}{$\mathbf{N a O H}$ modified } \\
\hline & $n$ & $k_{m}$ & $n$ & $k_{m}$ & $n$ & $k_{m}$ \\
1 & 0.524 & 0.758 & 0.547 & 0.775 & 0.522 & 0.755 \\
2 & 0.498 & 0.697 & 0.559 & 0.749 & 0.517 & 0.849 \\
3 & 0.517 & 0.847 & 0.568 & 0.687 & 0.567 & 0.825 \\
4 & 0.589 & 0.719 & 0.497 & 0.682 & 0.529 & 0.715 \\
5 & 0.510 & 0.729 & 0.518 & 0.798 & 0.579 & 0.709 \\
\hline
\end{tabular}

the rate of adsorptive mass transfer taking place through the stagnant film of the adsorbate which was caused by laminar motion (as the fluid transport takes place without the aid of any external agent) of the bulk liquid phase during the batch adsorption experiments. It was also observed that the value of transport number remained constant irrespective of the bulk adsorbate concentration showing that the initial As(III) concentration has no effect on transport number.

\section{5. Adsorption Isotherms}

Adsorption isotherms are used to describe the metal uptake capacity at fixed temperature. Adsorption of As(III) ions was performed at $298 \mathrm{~K}$ and $7.0 \mathrm{pH}$ at different adsorbent doses $(0.2-1.0 \mathrm{~g})$. In the present study, three isotherms (Langmuir, Freundlich and Temkin isotherms) have been used to study the As(III) adsorption behaviour with native and modified slag. The linearized model for Langmuir isotherm is represented in Eq. (21):

$$
\frac{C_{e}}{q_{e}}=\frac{C_{e}}{q_{m}}+\frac{1}{k_{L} q_{m}}
$$

where $q_{m}$ is the maximum adsorption capacity $(m g / g), k_{L}$ is the Langmuir constant $(L / g)$. Separation factor $\left(R_{L}\right)$ is used to determine the feasibility of the process and is given by Eq. (22):

$$
R_{L}=\frac{1}{k_{L} C_{i}+1}
$$

The isotherm is considered to be favourable if $0<R_{L}$ $<1$. The Freundlich isotherm is represented in Eq. (23):

$$
\log q_{e}=\left(\frac{1}{n}\right) \log C_{e}+\log k_{f}
$$

where $k_{f}$ and $n$ are Freundlich constants. The extent of feasibility of the adsorption of As(III) ions can be determined from the value of $n$. For a favourable process, $(1 / n)<1$. Temkin isotherm is shown in Eq. (24):

$$
\begin{aligned}
& q_{e}=B \ln C_{e}+B \ln A_{T} \\
& B=\frac{R T}{b}
\end{aligned}
$$

where $b$ is the Temkin constant $(\mathrm{J} / \mathrm{mol}), A_{T}$ is the equilibrium binding constant $(L / g), R$ is universal gas constant (8.314 J/mol. $\mathrm{K}), \mathrm{T}$ is the absolute temperature $(\mathrm{K})$.

The adsorption isotherm plots are shown in Figure 10 and the calculated parameters are shown in Table 6. Based on the value of linear regression coefficient $\left(R^{2}\right)$, it was observed that adsorption of As(III) ions on native and modified brick kiln slag followed Freundlich isotherm indicating multilayer adsorption and heterogeneous nature of the adsorbent. The acid modified slag (SA) was observed to show a maximum As(III) uptake capacity of $13.6 \mathrm{mg} / \mathrm{g}$ which was observed to be 1.4 times that of SB and 2.1 times that of BKS. The $n$ values from Freundlich isotherm indicated a good adsorption affinity towards As(III) ions. The obtained $A_{T}$ values (from the Temkin isotherm) was found to be maximum $(8.86 \mathrm{~L} / \mathrm{g})$ for $\mathrm{H}_{2} \mathrm{SO}_{4}$ modified slag (SA) indicating its maximum adsorption affinity towards As(III). The relative affinity for As(III) adsorption follows the order of: $\mathrm{SA}>\mathrm{SB}>$ Native. The $b_{T}$ values were almost same irrespective of the type of adsorbent which showed less variation in heat of adsorption. ${ }^{29}$ $\mathrm{HNO}_{3}$ modified activated carbon fibres showed a maximum uptake capacity of $8.65 \mathrm{mg} / \mathrm{g}$ where Langmuir isotherm was observed to show the best correlation coefficient. ${ }^{8}$ Iron scrap slag was found to show adsorption capacity of $13.7 \mathrm{mg} / \mathrm{g} .{ }^{10}$ Thus, the adsorbent used in the present study can be used to remove As(III) from groundwater without any energy expense.

\section{6. Adsorption Thermodynamics}

Adsorption thermodynamics expresses the removal capacity as a function of its temperature. Thermodynamic parameters were evaluated at $\mathrm{pH}=7.0$ using $0.3 \mathrm{~g}$ each of

\begin{tabular}{|c|c|c|c|c|c|c|c|c|c|c|}
\hline \multirow[t]{2}{*}{ Adsorbents } & \multirow[b]{2}{*}{$q_{m}(\mathrm{mg} / \mathrm{g})$} & \multicolumn{3}{|c|}{$\begin{array}{l}\text { Langmuir Isotherm } \\
\text { parameters }\end{array}$} & \multicolumn{3}{|c|}{$\begin{array}{l}\text { Freundlich Isotherm } \\
\text { parameters }\end{array}$} & \multicolumn{3}{|c|}{$\begin{array}{l}\text { Temkin Isotherm } \\
\text { parameters }\end{array}$} \\
\hline & & $k_{L}(\mathrm{~L} / \mathbf{m g})$ & $R_{L}$ & $R^{2}$ & $k_{f}(\mathrm{mg} / \mathrm{g})$ & $(1 / n)$ & $\mathbf{R}^{2}$ & $A_{T}(\mathrm{~L} / \mathrm{g})$ & $b(\mathrm{~J} / \mathrm{mol})$ & $\mathbf{R}^{2}$ \\
\hline Acid modified BKS & 13.57 & 3.58 & 0.252 & 0.875 & 8.57 & 0.18 & 0.974 & 8.86 & 94.08 & 0.954 \\
\hline Alkali modified BKS & 10.34 & 2.79 & 0.207 & 0.864 & 6.48 & 0.21 & 0.965 & 7.38 & 93.08 & 0.951 \\
\hline Native & 6.48 & 2.08 & 0.184 & 0.887 & 3.27 & 0.11 & 0.979 & 5.89 & 92.19 & 0.937 \\
\hline
\end{tabular}
$\mathrm{SA}$ and SB and $0.6 \mathrm{~g}$ of BKS at different temperatures (298 $-313 \mathrm{~K})$. This is generally expressed in the form of change in Gibb's Free energy $\left(\Delta G^{\circ}\right)$ which is shown in Eq. (26):

Table 6. Isotherm Parameters for As(III) ions adsorption using native and chemically modified slag 

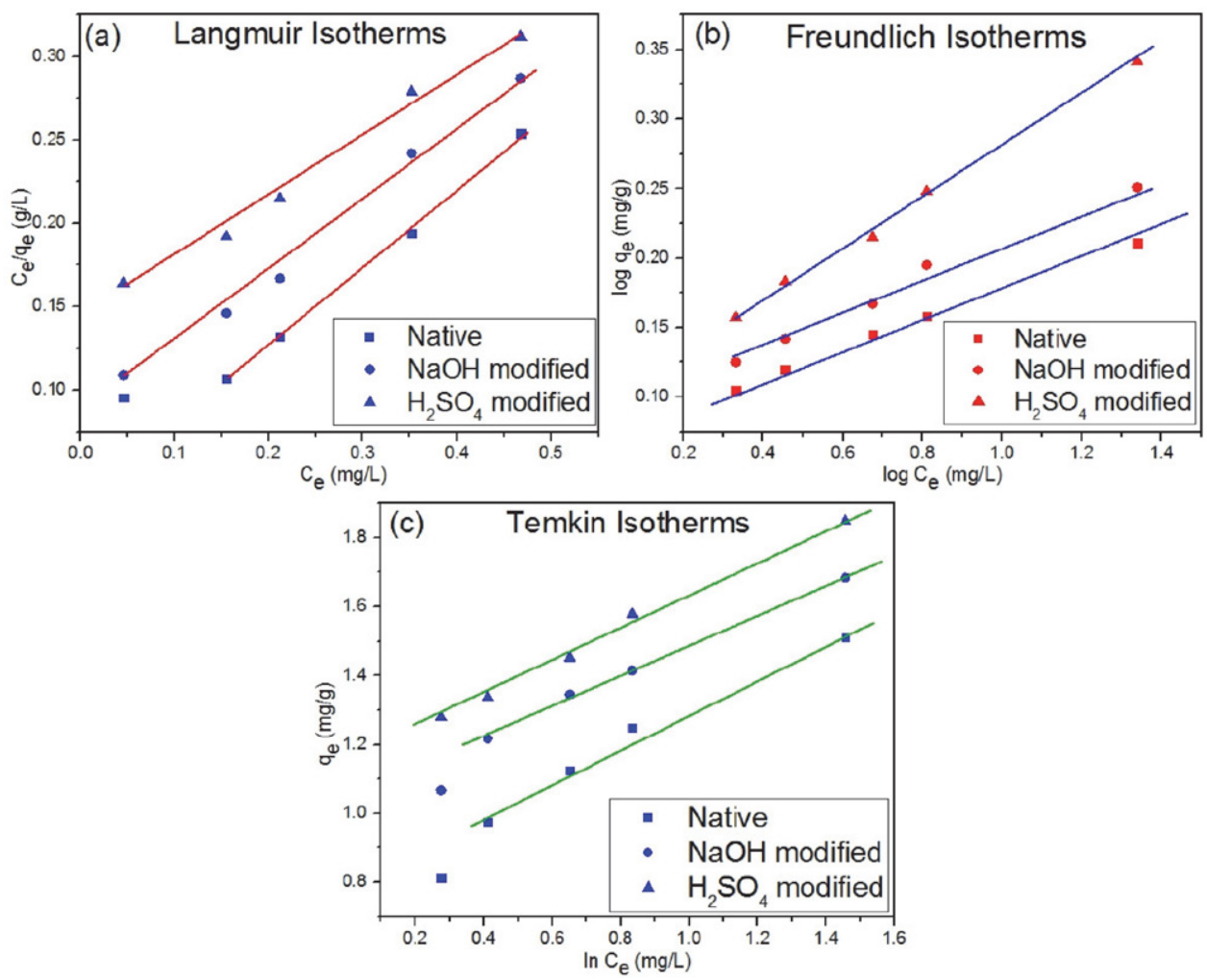

Figure 10. (a) Langmuir; (b) Freundlich; (c) Temkin isotherms at $298 \mathrm{~K}$ and $7.0 \mathrm{pH}$ for As(III) adsorption using native and chemically modified brick kiln slag

$$
\Delta G^{\circ}=-R T \ln K_{c}
$$

For a favourable and spontaneous process, $\Delta G^{\circ}<0$. Distribution coefficient $\left(K_{c}\right)$ is represented in Eq. (27):

$$
\begin{aligned}
& K_{c}=\frac{q_{e}}{C_{e}} \\
& \ln K_{c}=\frac{\Delta S}{R}+\frac{\Delta H}{R T}
\end{aligned}
$$

Entropy $(\Delta S)$ and enthalpy $(\Delta H)$ was calculated from the linear plot of $\ln K_{c}$ versus $(1 / T)$. The evaluated thermodynamic parameters are shown in Table 7 . From the Table 7 , it can be observed that the values of Gibb's free energy change $\left(\Delta G^{\circ}\right)$ were negative in nature thus indicating the feasibility of the adsorption of As(III) ions over the native and modified slag. Gibb's free energy change is said to be an important thermodynamic parameter reflecting the spontaneity of the adsorption process. A higher value of
$\Delta G^{\circ}$ is an indicative of more energetically favoured adsorption. The adsorption is said to occur favourably and spontaneously if the value of $\Delta G^{\circ}$ is negative. Thus from Table 7, it can be inferred that the adsorption of As(III) ions over native and modified slag was favourable and spontaneous at all temperatures. However, maximum negative values of $\Delta G^{\circ}$ was observed at $298 \mathrm{~K}$ which is an indicative of maximum As(III) adsorption capacity at this temperature.

Negative values of enthalpy $(\Delta H)$ show the liberation of energy during the adsorption of As(III) ions i.e. the process is exothermic. Moreover, the calculated values of enthalpy change suggested that the adsorption of As(III) ions on the native and modified slag correspond to physical adsorption since the obtained values were below $40 \mathrm{~kJ} /$ $\mathrm{mol}^{24}$ Positive values of entropy showed the increase in the disorderness of the adsorbate-adsorbent interface due to adsorption of As(III) ions which was supposed to be less

\begin{tabular}{|c|c|c|c|c|c|c|}
\hline \multirow{2}{*}{ Adsorbents } & \multicolumn{4}{|c|}{$\Delta \mathrm{G}^{\circ}(\mathrm{kJ} / \mathrm{mol})$} & \multirow{2}{*}{$\Delta \mathrm{H}(k J / m o l)$} & \multirow{2}{*}{$\Delta S(J / m o l K)$} \\
\hline & $298 \mathrm{~K}$ & $303 \mathrm{~K}$ & $308 \mathrm{~K}$ & $313 \mathrm{~K}$ & & \\
\hline Acid modified BKS & -6.52 & -4.74 & -1.85 & -0.85 & -20.17 & 41.28 \\
\hline Alkali modified BKS & -6.15 & -3.75 & -1.43 & -0.73 & -17.58 & 35.76 \\
\hline Native & -4.52 & -2.15 & -0.87 & -0.64 & -10.49 & 21.28 \\
\hline
\end{tabular}
ordered than that in the bulk solution and thus reflected

Table 7. Estimated Thermodynamic Parameters for As(III) ions adsorption 
the affinity of the adsorbent towards As(III) ions in the bulk solution. ${ }^{30}$

\section{Conclusions}

Acid modified brick kiln slag (SA) showed the maximum rate of adsorption followed by alkali modified (SB) and native slag $(\mathrm{SN})$. Mass transfer coefficients calculated were in the order of $10^{-10} \mathrm{~m} / \mathrm{s}$ for all the adsorbents which decreased with increasing concentration of As(III) ions in the bulk solution indicating that the driving force for mass transfer was inversely proportional to the As(III) concentration. Maximum value of mass transfer coefficients was obtained for the slag modified with $\mathrm{H}_{2} \mathrm{SO}_{4}$ thus showing its fairly good adsorption capacity over a particular temperature range.

Maximum adsorption occurred at $\mathrm{pH}=7.0$ due to electrostatic attraction phenomena. Fruendlich adsorption described the adsorption process indicating multilayer formation. Sherwood number interrelated initial concentration of As(III) ions according to Power Law model and were less than 1.0 for all the adsorbents showing that the mass transfer was limited by film diffusion. Thermodynamic evaluation showed that the adsorption was feasible at all temperatures with maximum adsorption taking place at $25^{\circ} \mathrm{C}(298 \mathrm{~K})$. Transport numbers obtained were independent of initial concentration of As(III) ions and the values were almost equal to 0.5 indicating Fickian mechanism or surface diffusion. This mass transfer study can be extensively used for the design of batch adsorbers to find the effect of various mass transfer parameters on the adsorption capacity and to determine the rate controlling mechanism.

\section{Conflict of Interests}

The authors declare no conflict of interests regarding the publication of this paper.

\section{Acknowledgement}

The authors are thankful to Technical Education Quality Improvement Programme (TEQIP-III) for proving the required funding to carry out the experiments and Centre for Interdisciplinary Research (CIR) of MNNIT Allahabad for allowing us to carry out sample characterizations.

\section{References}

1. D. Mohan, C. U. Pittman, Arsenic removal from water/wastewater using adsorbents-A critical review, J. Hazard. Mater. 2007,142, 1-53. DOI:10.1016/j.jhazmat.2007.01.006

2. S. Verma, P. K. Verma, D. Chakrabarty, Arsenic Bio-volatiliza- tion by Engineered Yeast Promotes Rice Growth and Reduces Arsenic Accumulation in Grains, Int. J. Environ. Res. 2019, 13, 475-485. DOI:10.1007/s41742-019-00188-7

3. S. Shevade, R. G. Ford, Use of synthetic zeolites for arsenate removal from pollutant water, Water Res. 2004, 38, 3197-3204. DOI:10.1016/j.watres.2004.04.026

4. T. S. Y. Choong, T. G. Chuah, Y. Robiah, F. L. Gregory Koay, I. Azni, Arsenic toxicity, health hazards and removal techniques from water: an overview, Desalination. 2007, 217, 139-166. DOI:10.1016/j.desal.2007.01.015

5. V. P. Mulgundmath, R. A. Jones, F. H. Tezel, J. Thibault, Fixed bed adsorption for the removal of carbon dioxide from nitrogen: Breakthrough behaviour and modelling for heat and mass transfer, Sep. Purif. Technol. 2012, 85, 17-27.

DOI:10.1016/j.seppur.2011.07.038

6. E. Torrik, M. Soleimani, M. T. Ravanchi, Application of Kinetic Models for Heavy Metal Adsorption in the Single and Multicomponent Adsorption System, Int. J. Environ. Res. 2019, 13, 813-828. DOI:10.1007/s41742-019-00219-3

7. C. J. Geankoplis, Transport Processes and Separation Process Principles: Includes Unit Operations, Transp. Process. Sep. Process Princ. (Includes Unit Oper. (2003).

8. J. Shi, Z. Zhao, J. Zhou, T. Sun, Z. Liang, Enhanced adsorption of As(III) on chemically modified activated carbon fibers, Appl. Water Sci. 2019, 9, 41.

DOI:10.1007/s13201-019-0919-7

9. M. B. Shakoor, N. K. Niazi, I. Bibi, M. Shahid, F. Sharif, S. Bashir, S. M. Shaheen, H. Wang, D. C. W. Tsang, Y. S. Ok, J. Rinklebe, Arsenic removal by natural and chemically modified water melon rind in aqueous solutions and groundwater, Sci. Total Environ. 2018, 645, 1444-1455.

DOI:10.1016/j.scitotenv.2018.07.218

10. V. Liem-Nguyen, V. Sjöberg, N. P. Dinh, D. H. Huy, S. Karlsson, Removal mechanism of arsenic (V) by stainless steel slags obtained from scrap metal recycling, J. Environ. Chem. Eng. 2020, 8, 103833. DOI:10.1016/j.jece.2020.103833

11. S. Wang, B. Gao, Y. Li, A. Mosa, A. R. Zimmerman, L.Q. Ma, W. G. Harris, K. W. Migliaccio, Manganese oxide-modified biochars: Preparation, characterization, and sorption of arsenate and lead, Bioresour. Technol. 2015, 181, 13-17. DOI:10.1016/j.biortech.2015.01.044

12. T. V. Nguyen, T. V. T. Nguyen, T. L. Pham, S. Vigneswaran, H. H. Ngo, J. Kandasamy, H. K. Nguyen, D. T. Nguyen, Adsorption and removal of arsenic from water by iron ore mining waste, Water Sci. Technol. 2009, 60, 2301-2308.

DOI:10.2166/wst.2009.667

13. B. Narayana, T. Cherian, M. Mathew, C. Pasha, Spectrophotometric determination of arsenic in environmental and biological samples, Indian J. Chem. Technol. 2006, 13, 36-40. DOI: http://hdl.handle.net/123456789/6993.

14. M. Jansson-Charrier, E. Guibal, J. Roussy, B. Delanghe, P. Le Cloirec, Vanadium (IV) sorption by chitosan: Kinetics and equilibrium, Water Res. 1996, 30, 465-475. DOI:10.1016/0043-1354(95)00154-9

15. F. Matalkah, M. Mahmoud, A.G.N.D. Darsanasiri, N. Abdol, P. Soroushian, A. M. Balachandra, High-recycled-content hy- 
draulic cements of alternative chemistry for concrete production, Int. J. Sustain. Eng. 2018, 11, 282-291.

DOI:10.1080/19397038.2018.1431973

16. M. L. Granizo, M. T. Blanco-Varela, S. Martínez-Ramírez, Alkali activation of metakaolins: Parameters affecting mechanical, structural and microstructural properties, J. Mater. Sci. 2007, 42, 2934-2943. DOI:10.1007/s10853-006-0565-y

17. J. Ojima, Determining of crystalline silica in respirable dust samples by Infrared Spectrophotometry in the presence of interferences, J. Occup. Health. 2003, 45, 94-103. DOI:10.1539/joh.45.94

18. A. Soultana, A. Valouma, G. Bartzas, K. Komnitsas, Properties of inorganic polymers produced from brick waste and metallurgical slag, Minerals. 2019, 9, 551. DOI:10.3390/min9090551

19. B. R. Berger, P. M. Bethke, The Behavior of Silica in Hydrothermal Solutions, in: Geol. Geochemistry Ep. Syst., 2020.

DOI: $10.5382 /$ Rev.02.03

20. L. Shrestha, M. Thapa, R. Shrestha, S. Maji, R. Pradhananga, K. Ariga, Rice Husk-Derived High Surface Area Nanoporous Carbon Materials with Excellent Iodine and Methylene Blue Adsorption Properties, Carbon. 2019, 5, 10.

DOI: $10.3390 / c 5010010$

21. A. D. Gupta, S. Pandey, V. K. Jaiswal, V. Bhadauria, H. Sin$\mathrm{gh}$, Simultaneous oxidation and esterification of cellulose for use in treatment of water containing $\mathrm{Cu}(\mathrm{II})$ ions, Carbohydr. Polym. 2019, 222, 114964.

DOI:10.1016/j.carbpol.2019.06.003

22. S. Rahdar, M. Taghavi, R. Khaksefidi, S. Ahmadi, Adsorption of arsenic (V) from aqueous solution using modified saxaul ash: isotherm and thermodynamic study, Appl. Water Sci. 2019, 9, 87. DOI:10.1007/s13201-019-0974-0
23. K. Yang, W. Qin, W. Liu, Extraction of metal arsenic from waste sodium arsenate by roasting with charcoal powder, Metals. 2018, 8, 542. DOI:10.3390/met8070542

24. S. Ghosh, R. Prabhakar, S. R. Samadder, Performance of $\gamma$-aluminium oxide nanoparticles for arsenic removal from groundwater, Clean Technol. Environ. Policy. 2019, 121-138. DOI:10.1007/s10098-018-1622-3

25. Z. Peng, X. Liu, H. Chen, Q. Liu, J. Tang, Characterization of ultraviolet-modified biochar from different feedstocks for enhanced removal of hexavalent chromium from water, Water Sci. Technol. 2019, 1705-1716. DOI:10.2166/wst.2019.170

26. Z. Aksu, I.A. Isoglu, Use of agricultural waste sugar beet pulp for the removal of Gemazol turquoise blue- $G$ reactive dye from aqueous solution, J. Hazard. Mater. 2006, 137, 418-430. DOI:10.1016/j.jhazmat.2006.02.019

27. D. Fu, Y. Zhang, F. Lv, P. K. Chu, J. Shang, Removal of organic materials from TNT red water by Bamboo Charcoal adsorption, Chem. Eng. J. 2012, 193, 39-49.

DOI:10.1016/j.cej.2012.03.039

28. C. R. Girish, V. R. Murthy, Mass Transfer studies on Adsorption of Phenolfrom Wastewater using Lantana Camara, Forest Waste, Int. J. Chem. Eng. 2016, 2016, 5809505. DOI:10.1155/2016/5809505

29. İ. Şentürk, M. Alzein, Adsorption of Acid Violet 7 onto Acid-Activated Pistachio Shell: Isotherm, Kinetic and Thermodynamic Studies, Acta Chim. Slov. 2020, 67, 55-69. DOI:10.17344/acsi.2019.5195

30. P. M. Carijo, G. S. dos Reis, É. C. Lima, M. L. S. Oliveira, G.L. Dotto, Functionalization of corn stover with 3-aminopropyltrietoxysilane to uptake Reactive Red 141 from aqueous solutions, Environ. Sci. Pollut. Res. 2019, 26, 32198-32208. DOI:10.1007/s11356-019-06386-2

\section{Povzetek}

Žlindro iz procesa žganja opeke (ang. brick kiln slag - BKS) smo uporabili za adsorpcijo nizkih koncentracij As(III) v šaržnem načinu. BKS smo modificirali $\mathrm{s}_{2} \mathrm{SO}_{4}(\mathrm{SA})$ in $\mathrm{NaOH}(\mathrm{SB}) \mathrm{s}$ ciljem povečanja adsorpcije. Maksimalno kapaciteto adsorpcije $(13.7 \mathrm{mg} / \mathrm{g})$ smo opazili pri SA in temperaturi $298 \mathrm{~K}, \mathrm{pH}=7.0$, količini adsorbenta $0.3 \mathrm{~g}$ in času $70 \mathrm{~min}$ in je bila 1.4-krat višja od SB. Podatke adsorpcije smo modelirali s Freundlichovo adsorpcijsko izotermo in kinetiko psevdo-drugega reda. Koeficient masnega transporta je padal z naraščajočo koncentracijo As(III), prevladujoči upor pa je bila difuzija skozi mejni sloj, ne glede na začetno koncentracijo As(III) ionov. Brezdimenzijsko Sherwoodovo število (Sh) je bilo odvisno od As(III) koncentracije $\left(C_{o}\right)$ in sicer $S h=2.97\left(C_{o}\right)^{-0.376}$ za SA, $S h=4.12\left(C_{o}\right)^{-0.215}$ za SB in $S h=4.83\left(C_{o}\right)^{-0.588}$ za BKS. Adsorpcije je bila favorizirana pri $298 \mathrm{~K}$ temperature (glede na vrednost $\Delta G^{\circ}$ ). Obdelano žlindro lahko torej uporabimo za učinkovito odstranjevanje As(III) ionov iz površinskih voda.

Except when otherwise noted, articles in this journal are published under the terms and conditions of the Creative Commons Attribution 4.0 International License 